Correction

\title{
Correction: Choi et al. Feasibility and Effect of Electroacupuncture on Cognitive Function Domains in Patients with Mild Cognitive Impairment: A Pilot Exploratory Randomized Controlled Trial. Brain Sci. 2021, 11, 756
}

Yujin Choi ${ }^{1}\left(\mathbb{D}\right.$, In-Chul Jung $^{2}{ }^{(D)}$, Ae-Ran Kim ${ }^{1}$, Hyo-Ju Park ${ }^{1}$, Ojin Kwon ${ }^{1}\left(\mathbb{D}\right.$, Jun-Hwan Lee ${ }^{1,3}$ and Joo-Hee $\mathrm{Kim}^{4,5, *}$

check for

updates

Citation: Choi, Y.; Jung, I.-C.; Kim, A.-R.; Park, H.-J.; Kwon, O.; Lee, J.-H.; Kim, J.-H. Correction: Choi et al. Feasibility and Effect of

Electroacupuncture on Cognitive Function Domains in Patients with Mild Cognitive Impairment: A Pilot Exploratory Randomized Controlled Trial. Brain Sci. 2021, 11, 756. Brain Sci. 2021, 11, 1334. https://doi.org/ 10.3390/brainsci11101334

Received: 16 September 2021 Accepted: 27 September 2021 Published: 11 October 2021

Publisher's Note: MDPI stays neutral with regard to jurisdictional claims in published maps and institutional affiliations.

Copyright: (c) 2021 by the authors. Licensee MDPI, Basel, Switzerland. This article is an open access article distributed under the terms and conditions of the Creative Commons Attribution (CC BY) license (https:/ / creativecommons.org/licenses/by/ $4.0 /)$.
1 Clinical Medicine Division, Korea Institute of Oriental Medicine, Daejeon 34054, Korea; choiyujin@kiom.re.kr (Y.C.); arkim@kiom.re.kr (A.-R.K.); mable@kiom.re.kr (H.-J.P.); cheda1334@kiom.re.kr (O.K.); omdjun@kiom.re.kr (J.-H.L.)

2 Department of Neuropsychiatry, College of Korean Medicine, Daejeon University, Daejeon 34520, Korea; npjeong@dju.kr

3 Korean Medicine Life Science, University of Science \& Technology (UST), Campus of Korean Institute of Oriental Medicine, Daejeon 34054, Korea

4 Department of Acupuncture and Moxibustion Medicine, College of Korean Medicine, Sangji University, Wonju-si 26339, Korea

5 Research Institute of Korean Medicine, Sangji University, Wonju-si 26339, Korea

* Correspondence: jhkim714v@gmail.com; Tel.: +82-33-741-9268

The authors wish to make the following correction to [1]. The heading of Table 5 of the manuscript was misplaced, and two adverse events which are unlikely related to the intervention in the EA group were omitted. The corrected table is as follows.

Table 5. Adverse events (all causalities) reported during the study.

\begin{tabular}{|c|c|c|c|}
\hline & $\begin{array}{c}\text { EA Group } \\
(n=20)\end{array}$ & $\begin{array}{c}\text { Sham EA Group } \\
(n=20)\end{array}$ & $\begin{array}{c}\text { Usual Care Group } \\
(n=20)\end{array}$ \\
\hline \multicolumn{4}{|l|}{ Adverse events (possibly or probably related) } \\
\hline Headache & 1 & 1 & 1 \\
\hline Bruise & 4 & 0 & 0 \\
\hline Pruritus & 2 & 0 & 0 \\
\hline \multicolumn{4}{|l|}{ Severity of AEs } \\
\hline Mild & 17 & 8 & 1 \\
\hline Moderate & 2 & 0 & 0 \\
\hline Severe & 1 & 1 & 0 \\
\hline \multicolumn{4}{|l|}{ Causality of AEs } \\
\hline Definitely related & 0 & 0 & 0 \\
\hline Probably related & 6 & 0 & 0 \\
\hline Possibly related & 1 & 1 & 1 \\
\hline Unlikely related & 9 & 1 & 0 \\
\hline Definitely not related & 4 & 7 & 0 \\
\hline Total number of participants with AE & 10 & 5 & 1 \\
\hline Total number of AEs & 20 & 9 & 1 \\
\hline Total number of AEs (intervention-related) & 7 & 1 & 1 \\
\hline Total number of SAEs & 1 & 1 & 0 \\
\hline Total number of SAEs (intervention-related) & 0 & 0 & 0 \\
\hline Total number of interventions (or visits) & 407 & 371 & 88 \\
\hline
\end{tabular}


The authors would like to apologize for any inconveniences caused to the readers by these changes.

\section{Reference}

1. Choi, Y.; Jung, I.-C.; Kim, A.-R.; Park, H.-J.; Kwon, O.; Lee, J.-H.; Kim, J.-H. Feasibility and effect of electroacupuncture on cognitive function domains in patients with Mild Cognitive Impairment: A pilot exploratory randomized controlled trial. Brain Sci. 2021, 11, 756. [CrossRef] [PubMed] 